\title{
Variability in Embodied Energy and Carbon Intensities of Building Materials Using Hybrid LCA: Malaysian Experience
}

\author{
Wan-Mohd-Sabki Wan Omar, a ${ }^{1}$, Jeung-Hwan Doh ${ }^{2, b}$ and Kriengsak \\ Panuwatwanich ${ }^{3, c}$ \\ 1, 2, 3Griffith School of Engineering, Griffith University, Queensland 4222, Australia \\ ${ }^{1}$ School of Environmental Engineering, University Malaysia Perlis, 02600 Arau, Perlis, Malaysia

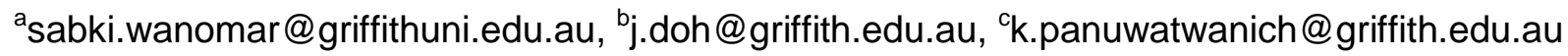

Keywords: Embodied energy; carbon; variability; hybrid LCA; Malaysia

Abstract. This paper empirically investigates the variations of embodied energy (EE) and carbon (EC) intensities of materials and identifies their parameter variations in hybrid life cycle assessment (LCA). These parameters include energy tariff, primary energy factor, disaggregation constant, emission factor, and price fluctuation. Hybrid LCA has been conducted to expand the system boundary by filling the gaps in traditional LCA data inventories. The Malaysian Input-Output (I-O) tables are used to derive indirect energy and carbon intensities which are then combined to take advantages of detailed process LCA. The results revealed that maximum increase in energy tariffs and material price fluctuations were the key parameters and issues leading to higher variations in $\mathrm{EE}$ and EC intensity values. Other parameters - such as maximum increase in primary energy factor, emission factor and excluding disaggregation constant - have a slight impact upon EE and EC intensity variations. Building materials with high indirect energy in the upstream boundary of materials production have high influence on hybrid LCA variation. Therefore, any decision relating to these materials should be considered carefully.

\section{Introduction}

Building industry consumes $40 \%$ of primary energy during life cycle stages of material productions, transportation, operation, maintenance, demolition and disposal. Most of the energy consumed is mainly related to the operational phase of a building, while production of building materials such as cement, concrete and steel are attributed to the industry sectors such as concrete and other non-metallic mineral sector and iron and steel product sector. In developed countries, production of building materials contributes to $8-12 \%$ of the total carbon emission. In Asian countries such as Malaysia, the industrial sector (e.g. manufacturing and construction) accounts for $38.6 \%$ of total energy demand and was claimed to be a major contributor to the environmental impact [1]. The energy-intensive industries, for instance cement and steel, were predicted to be a major consumer in the future.

The literature on EE and EC intensities in materials production indicates a considerable discrepancy between the bottom-up (process LCA) and top-down (I-O LCA) analyses [2-4]. The high variations of $\mathrm{EE}$ and $\mathrm{EC}$ intensities can be found between the two analyses which in turn influence the LCA of building components and structures. Previous studies identified various parameters influencing variations in EE consideration such as methodological selection, primary and delivered energy, age of data, manufacturing technology, source of data, and completeness of data [5, 6]. Meanwhile, Crawford [3] also identified variation in top-down analysis due to homogeneity assumption, proportionality assumption, conversion of economic data to energy data, use of national average, capital equipment and sector aggregation.

Previous researches demonstrated the changes of EE and EC intensities of materials and products over a certain period of time [7]. The changes of EE and EC could be influenced by one or combination of the following parameters: system boundaries, method of EE analysis, geographic location, primary and delivered energy, age of data sources, sources of data, completeness of data, and temporal representativeness [5]. However, these factors have not been empirically studied to identify their relative contributions to the variation of EE and EC intensities. Currently, there are 
limited researches have been conducted to empirically investigate and evaluate the impact of parameter variations in EE and EC intensities, particularly to study how these parameters can be incorporated into EE and EC analysis and to what extent this parameter influences the variations of $\mathrm{EE}$ and EE intensities. Therefore, the purpose of this paper is to identify factors and issues that have a strong influence on hybrid models resulting from material production, and to determine the different effects of parameter variations on hybrid LCA model.

EC intensity of material for reference case using hybrid LCA. Derivation of EC intensity involved identification of parameter variations in hybrid LCA model. Indirect energy and carbon per unit of final consumption were calculated using Leontief inverse matrix and parameters of energy and carbon in each sector. Each of parameters was derived based on the detailed energy balances provided by International Energy Agency (IEA) database and were validated by using Malaysian energy balances to ensure the reliability of data provided [8, 9]. These parameters convert the product flow in the supply chain $(\mathrm{RM} \$ \mathrm{RM} \$)$ to physical energy values (GJ/RM\$) [10]. These values were further deflated to the base year 2005 according to the current Malaysian I-O tables for 2005 produced in 2010 [11]. The 2005 I-O tables have 5 years lag times thus influence the variability and consistency of EE and EC intensities of building materials. These variations were discussed in the next section.

The hybrid LCA combines the results obtained from the process LCA and I-O LCA so that the completeness in upstream boundary of materials production can be increased $[2,12]$. The indirect carbon intensity of a particular material sector can be identified by subtracting Eq. 2 from Eq. 1 respectively. The difference between total and direct carbon intensity is then multiplied by material cost. In order to identify total EC intensity for a material (e.g. cement, aggregate, water and reinforcement steel), the indirect carbon intensity is combined with direct carbon intensity (i.e. extraction from process LCA) using hybrid LCA as given in Eq. 3 below.

$\mathrm{DCO}_{2-\mathrm{e}} \mathrm{I}_{\mathrm{n}}=\sum_{\mathrm{e}}^{\mathrm{E}} \mathrm{D}_{\mathrm{RCe}} \times \mathrm{T}_{\mathrm{e}} \times \mathrm{PEF}_{\mathrm{e}} \times \mathrm{C}_{\mathrm{e}} \times \mathrm{I}_{\mathrm{e}}$

$\mathrm{TCO}_{2-\mathrm{e}} \mathrm{I}_{\mathrm{n}}=\sum_{\mathrm{e}}^{\mathrm{E}} \mathrm{T}_{\mathrm{RCe}} \times \mathrm{T}_{\mathrm{e}} \times \mathrm{PEF}_{\mathrm{e}} \times \mathrm{C}_{\mathrm{e}} \times \mathrm{I}_{\mathrm{e}}$

$\mathrm{ECO}_{2-\mathrm{e}} \mathrm{I}_{\mathrm{m}}=\mathrm{ECO}_{2-\mathrm{e}} \mathrm{I}_{\mathrm{D}}+\left[\left(\mathrm{TCO}_{2-\mathrm{e}} \mathrm{I}_{\mathrm{n}}-\mathrm{DCO}_{2-\mathrm{e}} \mathrm{I}_{\mathrm{n}}\right) \times \mathrm{C}_{\mathrm{m}}\right]$

Where, $D C O_{2-e} I_{n}$ is the direct carbon intensity for a particular sector $n$ or product output (GJ/RM\$); $D_{R C e}$ is the direct requirement coefficient of energy sector $e(\mathrm{RM} \$ / \mathrm{RM} \$) ; E$ is the total number of energy supply sector $e$ in I-O table; $T_{e}$ is average energy tariff (GJ/RM\$); $P E F_{e}$ is the primary energy factor of energy supply sector $e$ (dimensionless); $C_{e}$ is the disaggregation constant for energy sub-sector $e ; I_{e}$ is the emission factor of energy supply sector $e ; T C O_{2-e} I_{n}$ is total carbon intensity for a particular sector $n$ or product output $\left(\mathrm{kg} \mathrm{CO} \mathrm{CO}_{2 \mathrm{e}} / \mathrm{RM} \$\right) ; T_{R C e}$ is total requirement coefficient (Leontief inverse) of energy supply sector $e(\mathrm{RM} \$ / \mathrm{RM} \$) ; E C O_{2-e} I_{m}$ is total EC intensity of a material or product using hybrid LCA; $E C O_{2-e} I_{D}$ is direct carbon intensity from process LCA; $C_{m}$ is the cost of material or product $(\mathrm{RM} \$ / \mathrm{kg})$.

Identification of parameter variations. Five parameters were identified to have impact on the variations of EE and EC intensities [5]. These include: (1) energy tariff for energy supply sector; (2) disaggregation constant; (3) primary energy factor; (4) emission factor; and (5) price fluctuation. Each of variation was quantified and incorporated into I-O LCA and hybrid LCA to identify key parameters that have influence to the variations in hybrid LCA model. Parameter variations were derived and quantified using coefficient of variation (COV) and percentage of range and then incorporated into the analysis. The detailed parameter variations are discussed in the following section.

Energy tariff for energy supply sectors. Energy tariff is used to convert monetary unit into physical unit of supply chain in Malaysian I-O tables. Each of energy tariffs for energy supply sector was derived from Malaysian energy balances obtained from International Energy Agency (IEA) and based on estimated individual energy tariff. These energy tariffs were compared to energy tariffs derived from the 2005 I-O tables. Based on Table 1, energy tariff for coal has $33.47 \%$ higher variation compare to others energy tariff. Crude oil was the second has $18.34 \%$ variation in 
energy tariffs. Significant variation in energy tariff over period of time would have high influence on the EE and EC analysis.

Table 1. Malaysia's average energy tariffs for energy supply sector for the period of 2005-2008

\begin{tabular}{|c|c|c|c|c|c|c|c|c|c|c|}
\hline \multirow{2}{*}{$\begin{array}{c}\mathrm{I}-\mathrm{O} \\
\text { Sector }^{\mathrm{a}}\end{array}$} & \multirow{2}{*}{$\begin{array}{l}\text { Disaggregated } \\
\text { energy supply sector }\end{array}$} & \multicolumn{4}{|c|}{ Average energy tariffs, $\mathrm{T}_{\mathrm{e}}(\mathrm{GJ} / \mathrm{RM} \$)$} & \multirow{2}{*}{ Stdev. } & \multirow{2}{*}{ Avg. } & \multirow{2}{*}{$\begin{array}{l}\mathrm{COV} \\
(\%)\end{array}$} & \multirow{2}{*}{$\begin{array}{l}\text { Max. of } \\
\text { ET }\end{array}$} & \multirow{2}{*}{$\begin{array}{l}\text { Min. of } \\
\text { ET }\end{array}$} \\
\hline & & 2005 & 2006 & 2007 & 2008 & & & & & \\
\hline 11100 & Crude oil & 0.0295 & 0.0253 & 0.0244 & 0.0186 & 0.004 & 0.02 & 18.34 & 0.0295 & 0.0186 \\
\hline 11200 & Natural gas & 0.0820 & 0.0820 & 0.0820 & 0.0820 & 0.000 & 0.08 & 0.00 & 0.0820 & 0.0820 \\
\hline 10100 & Coal mining & 0.1397 & 0.1400 & 0.1118 & 0.0598 & 0.038 & 0.11 & 33.47 & 0.1400 & 0.0598 \\
\hline 23100 & Petroleum refinery & 0.0156 & 0.0179 & 0.0135 & 0.0135 & 0.002 & 0.02 & 14.04 & 0.0179 & 0.0135 \\
\hline 40100 & Electricity supply & 0.0144 & 0.0144 & 0.0135 & 0.0125 & 0.001 & 0.01 & 6.59 & 0.0144 & 0.0125 \\
\hline 40200 & Gas supply & 0.0820 & 0.0820 & 0.0820 & 0.0820 & 0.000 & 0.08 & 0.00 & 0.0820 & 0.0820 \\
\hline
\end{tabular}

(a) Based on the Malaysian Standard Industrial Classification for 2000 (MSIC2000)

Disaggregated energy supply sector. Parameter used to disaggregate the energy supply sector aims to overcome double counting in EE and EC analysis. Disaggregation constant allows individual energy tariff to be used instead of average energy tariff [10]. In Malaysian I-O tables for 2005, the aggregated energy supply sectors can be found in crude oil (IOPI 1110) and natural gas sector (IOPI 11200) (aggregate natural gas and crude oil sector); and electricity (IOPI 40100) and gas supply sector (IOPI 40200) (aggregate electricity and gas supply sector). Disaggregated energy supply sector was derived from Malaysian energy balance obtained from International Energy Agency (IEA). The disaggregation constant was included or excluded in EE and EC analysis using hybrid LCA model to identify variability and consistency in EE and EC intensities of materials.

Primary and delivered energy. Primary energy is referred to as the energy required from natural resources (e.g. coal or natural gas) by producer (e.g. electricity or petroleum refinery) whereas delivered energy is the energy consumed by final consumers. Conversion of delivered energy to primary energy using primary energy factor (PEF) is site specific [13]. The consideration of primary energy takes into account the loss in transmission and distribution as well as for plant own use for specific countries. The variability of PEF leads to the variations in EE and EC intensities. The realible and up-to-date energy database provided by International Energy Agency (IEA) was obtained to estimate PEF for Malaysian energy suply sectors. Table 2 presents derivation of PEF from Malaysian energy balances for the period of 2005 to 2008. The PEF for electricity supply has $4.14 \%$ variation higher than others energy supply sector due to own energy used in transformation processes (i.e. transformation of natural gas into electricity supply).

Table 2. Malaysia's PEF for the energy supply sector for the period 2005-2008

\begin{tabular}{|c|c|c|c|c|c|c|c|c|c|c|}
\hline \multirow{2}{*}{ I-O Sector ${ }^{\mathrm{a}}$} & \multirow{2}{*}{$\begin{array}{l}\text { Disaggregated } \\
\text { energy supply sector }\end{array}$} & \multicolumn{4}{|c|}{ Primary energy factor (PEF) } & \multirow{2}{*}{ Stdev. } & \multirow{2}{*}{ Avg. } & \multirow{2}{*}{$\begin{array}{c}\mathrm{COV} \\
(\%)\end{array}$} & \multirow{2}{*}{$\begin{array}{l}\text { Max. of } \\
\text { PEF }\end{array}$} & \multirow{2}{*}{$\begin{array}{l}\text { Min. of } \\
\text { PEF }\end{array}$} \\
\hline & & 2005 & 2006 & 2007 & 2008 & & & & & \\
\hline 11100 & Crude oil & 1.00 & 1.00 & 1.00 & 1.00 & 0.00 & 1.00 & 0.00 & 1.00 & 1.00 \\
\hline 11200 & Natural gas & 1.62 & 1.62 & 1.64 & 1.74 & 0.05 & 1.66 & 3.31 & 1.74 & 1.62 \\
\hline 10100 & Coal mining & 1.00 & 1.00 & 1.00 & 1.00 & 0.00 & 1.00 & 0.00 & 1.00 & 1.00 \\
\hline 23100 & Petroleum refinery & 1.01 & 1.04 & 1.04 & 1.06 & 0.02 & 1.04 & 1.95 & 1.06 & 1.01 \\
\hline 40100 & Electricity supply & 4.18 & 4.04 & 3.96 & 4.37 & 0.18 & 4.14 & 4.28 & 4.37 & 3.96 \\
\hline 40200 & Gas supply & 1.14 & 1.10 & 1.08 & 1.08 & 0.03 & 1.10 & 2.49 & 1.14 & 1.08 \\
\hline
\end{tabular}

(a) Based on the Malaysian Standard Industrial Classification for 2000 (MSIC2000)

Emission factor. Emission factor was applied to estimate carbon intensity for specific materials or products. An emission factor converts indirect energy intensity into indirect carbon intensity from I-O tables per unit monetary value which is then multiplied with the material or product sector output. Emission factor for electricity depends on fuel mix into electricity generation plant. Electricity emission factor was derived from Malaysian energy balances and variation of electricity from Malaysian generation plants for the period of 2005 to 2008. The results are compared with previous studies and found to be slightly higher due to gross caloric value (GCV) and scope-3 emission are incorporated into emission factor calculation [14]. 
Price fluctuation. Previous researches proposed hybrid LCA model by using material and building prices to quantify total $\mathrm{EE}$ and $\mathrm{EC}$ intensity of building $[2,3]$. However, using building prices with highly aggregated sectors (i.e. residential building and other construction in I-O tables used by Treloar [2] and Crawford [3]) tends to greatly impact upon the total EE and EC intensity of building due to two levels of problems in price variations: (1) the use of material price to convert economic flow into physical energy and product quantity; and (2) the use of building price to fill the remaining sideways and downstream gaps. In this research, variation of price from reference case was based on percentage range of maximum and minimum values over the period of 2005 to 2008 . The building material prices in Malaysia were acquired from the Construction Industry Development Board (CIDB) database and found the material price for ready-mixed concrete increased by up to $42 \%$ over the period of 2005 to 2008 .

\section{Results and Discussions}

The variations of EE and EC intensities of materials in Malaysia due to parameter changes compared with the reference cases are presented in Table 3. An increased energy tariff for the energy supply sector has a single high effect on EE and EC intensities of materials. The variations of EE and EC intensities of plasterboard were higher compared with other parameters, with results showing the variations of EE and EC intensities were up to $27.11 \%$ and $19.17 \%$ respectively. In particular, EE and EC intensities of plasterboard increased from $19.16 \mathrm{MJ} / \mathrm{kg}$ to $24.36 \mathrm{MJ} / \mathrm{kg}$ and $1.50 \mathrm{~kg} \mathrm{CO}$ 2-e $/ \mathrm{kg}$ to $1.79 \mathrm{~kg} \mathrm{CO}_{2-\mathrm{e}} / \mathrm{kg}$. This variation was due to the influence of indirect energy and carbon embodied in the upstream boundary of the supply chain in material production.

A single variation in PEF has less impact upon EE and EC intensities of materials. A maximum increase of PEF (i.e. particularly the natural gas and electricity supply sectors) has less impact on the hybrid LCA model. Using maximum PEF values between the periods of 2005 to 2008 showed the EE and EC intensities of plasterboard slightly increased from $19.16 \mathrm{MJ} / \mathrm{kg}$ to $21.74 \mathrm{MJ} / \mathrm{kg}$ and $1.50 \mathrm{~kg} \mathrm{CO} 2-\mathrm{e} / \mathrm{kg}$ to $1.54 \mathrm{~kg} \mathrm{CO}_{2-\mathrm{e}} / \mathrm{kg}$, accounted for $13.02 \%$ and $4.80 \%$ of total EE and EC content. Meanwhile, the EE and EC intensities for clear float glass also slightly increased up to about $3.62 \%$ and $4.45 \%$ of total EE and EC content, ranged between $42.32 \mathrm{MJ} / \mathrm{kg}$ to $43.85 \mathrm{MJ} / \mathrm{kg}$ and $3.02 \mathrm{~kg}$ $\mathrm{CO}_{2-\mathrm{e}} / \mathrm{kg}$ to $3.15 \mathrm{~kg} \mathrm{CO} \mathrm{CO}_{2 \mathrm{e}} / \mathrm{kg}$ respectively. The parameter variations on energy intensive materials has less impact (e.g. cement, clay brick, steel virgin etc.), compared with less energy intensive materials such as clear float glass, plasterboard, or plastic products that have a large proportion of indirect energy and carbon embodied in the upstream boundary of materials production.

Using a disaggregation constant for aggregated energy supply sectors has less impact on variations of EC intensities of materials in the hybrid LCA model. Without disaggregation constants, EE and EC intensity values for clear float glass varied by up to $10.08 \%(10.08 \%$ reduction) and $11.78 \%$ (11.78\% reduction) respectively. As shown in Tables 3, overall EE and EC intensities of materials in the hybrid LCA model slightly decreased from the reference cases.

An increase of material price also has a moderate impact on EE and EC intensities in the hybrid LCA model. The variation of material prices in Malaysia such as cement, ready-mixed concrete, and reinforcement steel were much higher compared with other material prices. Further increases of cement price of $32.95 \%$ led to the variation of $\mathrm{EE}$ and $\mathrm{EC}$ intensity values by up to $13.93 \%$ (from $9.01 \mathrm{MJ} / \mathrm{kg}$ to $10.26 \mathrm{MJ} / \mathrm{kg}$ ) and $8.70 \%$ (from $1.01 \mathrm{~kg} \mathrm{CO}_{2-\mathrm{e}} / \mathrm{kg}$ to $1.09 \mathrm{~kg} \mathrm{CO} \mathrm{CO}_{2-\mathrm{e}} / \mathrm{kg}$ ) in the hybrid LCA model.

The variation in the electricity emission factor was due to the mix of fossil fuel in national energy policy, which has less impact on the hybrid LCA values. The maximum increase of emission factor has slightly increased EE and EC intensities of materials by approximately less than 3\%. Therefore, using a disaggregation constant for the aggregated energy supply sector so that individual emission factors can be used instead of an average emission factor would result in less variation in the hybrid LCA model. 
Table 3: EE and EC and changes in due to parameter variations compared with the reference case at materials and products level for Malaysia

\begin{tabular}{|c|c|c|c|c|c|c|c|c|c|c|c|c|c|}
\hline \multirow{3}{*}{$\begin{array}{l}\text { Building } \\
\text { material or } \\
\text { product }\end{array}$} & \multirow{3}{*}{ Changed parameter } & \multicolumn{6}{|c|}{ Embodied energy $(\mathrm{MJ} / \mathrm{kg})$} & \multicolumn{6}{|c|}{ Embodied carbon $\left(\mathrm{kg} \mathrm{CO}_{2-\mathrm{e}} / \mathrm{kg}\right)$} \\
\hline & & \multirow{2}{*}{$\begin{array}{r}\text { Process } \\
\text { LCA }\end{array}$} & \multicolumn{3}{|c|}{ I-O LCA } & \multirow{2}{*}{$\begin{array}{r}\text { Hybrid } \\
\text { LCA }\end{array}$} & \multirow{2}{*}{$\begin{array}{r}\text { Change } \\
\text { from ref. } \\
(\%)\end{array}$} & \multirow{2}{*}{$\begin{array}{r}\text { Process } \\
\text { LCA }\end{array}$} & \multicolumn{3}{|c|}{ I-O LCA } & \multirow{2}{*}{$\begin{array}{r}\text { Hybrid } \\
\text { LCA }\end{array}$} & \multirow{2}{*}{$\begin{array}{r}\text { Change } \\
\text { from ref } \\
(\%)\end{array}$} \\
\hline & & & Direct & Indirect & Total & & & & Direct & Indirect & Total & & \\
\hline & Reference case (minimum case) & 5.200 & 1.024 & 3.807 & 4.831 & 9.007 & 0.000 & 0.740 & 0.106 & 0.265 & 0.372 & 1.005 & 0.000 \\
\hline Ordinary & Maximum increase in ET & 5.200 & 1.443 & 4.668 & 6.111 & 9.868 & 9.565 & 0.740 & 0.141 & 0.332 & 0.473 & 1.072 & 6.642 \\
\hline \multirow{4}{*}{$\begin{array}{l}\text { Portland } \\
\text { cement } \\
(\mathrm{OPC})\end{array}$} & Maximum increase in PEF & 5.200 & 1.085 & 4.015 & 5.100 & 9.215 & 2.315 & 0.740 & 0.114 & 0.281 & 0.395 & 1.021 & 1.558 \\
\hline & Without disaggregation constant & 5.200 & 1.030 & 3.149 & 4.180 & 8.349 & -7.298 & 0.740 & 0.093 & 0.223 & 0.315 & 0.963 & -4.259 \\
\hline & Maximum increase in material price & 5.200 & 1.362 & 5.061 & 6.423 & 10.261 & 13.927 & 0.740 & 0.141 & 0.353 & 0.494 & 1.093 & 8.699 \\
\hline & Maximum increase in EF for elec. & - & - & - & - & - & - & 0.740 & 0.111 & 0.271 & 0.382 & 1.011 & 0.568 \\
\hline \multirow{6}{*}{$\begin{array}{l}\text { Concrete } \\
\text { (35 MPa) }\end{array}$} & Reference case (minimum case) & 1.074 & 0.145 & 0.777 & 0.922 & 1.851 & 0.000 & 0.142 & 0.015 & 0.055 & 0.070 & 0.197 & 0.000 \\
\hline & Maximum increase in ET & 1.151 & 0.222 & 0.953 & 1.175 & 2.104 & 13.702 & 0.148 & 0.022 & 0.069 & 0.090 & 0.217 & 10.360 \\
\hline & Maximum increase in PEF & 1.081 & 0.152 & 0.819 & 0.972 & 1.901 & 2.710 & 0.143 & 0.016 & 0.058 & 0.074 & 0.201 & 2.164 \\
\hline & Without disaggregation constant & 1.075 & 0.146 & 0.644 & 0.789 & 1.718 & -7.145 & 0.140 & 0.013 & 0.046 & 0.059 & 0.186 & -5.418 \\
\hline & Maximum increase in material price & 1.136 & 0.207 & 1.049 & 1.256 & 2.185 & 18.071 & 0.148 & 0.021 & 0.074 & 0.095 & 0.222 & 13.067 \\
\hline & Maximum increase in EF for elec. & - & - & - & - & - & - & 0.142 & 0.016 & 0.056 & 0.072 & 0.198 & 0.981 \\
\hline \multirow{6}{*}{ Plasterboard } & Reference case (minimum case) & 6.750 & 2.257 & 12.411 & 14.668 & 19.161 & 0.000 & 0.390 & 0.234 & 1.113 & 1.348 & 1.503 & 0.000 \\
\hline & Maximum increase in ET & 6.750 & 3.488 & 17.605 & 21.094 & 24.355 & 27.109 & 0.390 & 0.338 & 1.402 & 1.739 & 1.792 & 19.174 \\
\hline & Maximum increase in PEF & 6.750 & 2.390 & 14.906 & 17.295 & 21.656 & 13.021 & 0.390 & 0.249 & 1.186 & 1.435 & 1.576 & 4.800 \\
\hline & Without disaggregation constant & 6.750 & 2.285 & 12.049 & 14.334 & 18.799 & -1.889 & 0.390 & 0.207 & 0.929 & 1.136 & 1.319 & -12.291 \\
\hline & Maximum increase in material price & 6.750 & 2.415 & 14.990 & 17.404 & 21.740 & 13.458 & 0.390 & 0.249 & 1.183 & 1.431 & 1.573 & 4.614 \\
\hline & Maximum increase in EF for elec. & - & - & - & - & - & - & 0.390 & 0.245 & 1.151 & 1.395 & 1.541 & 2.478 \\
\hline \multirow{6}{*}{$\begin{array}{l}\text { Clear float } \\
\text { glass }\end{array}$} & Reference case (minimum case) & 15.000 & 7.879 & 27.323 & 35.202 & 42.323 & 0.000 & 0.910 & 0.995 & 2.106 & 3.101 & 3.016 & 0.000 \\
\hline & Maximum increase in ET & 15.000 & 10.608 & 33.878 & 44.486 & 48.878 & 15.488 & 0.910 & 1.257 & 2.646 & 3.903 & 3.556 & 17.909 \\
\hline & Maximum increase in PEF & 15.000 & 8.402 & 28.853 & 37.256 & 43.853 & 3.616 & 0.910 & 1.078 & 2.240 & 3.318 & 3.150 & 4.447 \\
\hline & Without disaggregation constant & 15.000 & 7.957 & 23.057 & 31.014 & 38.057 & -10.081 & 0.910 & 0.824 & 1.751 & 2.575 & 2.661 & -11.775 \\
\hline & Maximum increase in material price & 15.000 & 8.999 & 31.206 & 40.204 & 46.206 & 9.173 & 0.910 & 1.137 & 2.405 & 3.542 & 3.315 & 9.922 \\
\hline & Maximum increase in EF for elec. & - & - & - & - & - & - & 0.910 & 1.062 & 2.173 & 3.235 & 3.083 & 2.209 \\
\hline \multirow{6}{*}{$\begin{array}{l}\text { Aluminium } \\
\text { virgin }\end{array}$} & Reference case (minimum case) & 155.000 & 11.364 & 86.025 & 97.388 & 241.025 & 0.000 & 9.160 & 1.696 & 7.509 & 9.205 & 16.669 & 0.000 \\
\hline & Maximum increase in ET & 155.000 & 14.362 & 107.913 & 122.275 & 262.913 & 9.082 & 9.160 & 1.696 & 8.030 & 9.726 & 17.190 & 3.126 \\
\hline & Maximum increase in PEF & 155.000 & 12.218 & 91.039 & 103.257 & 246.039 & 2.081 & 9.160 & 1.849 & 8.031 & 9.880 & 17.191 & 3.134 \\
\hline & Without disaggregation constant & 155.000 & 11.523 & 75.056 & 86.578 & 230.056 & -4.551 & 9.160 & 1.347 & 6.204 & 7.551 & 15.364 & -7.830 \\
\hline & Maximum increase in material price & 155.000 & 13.325 & 100.872 & 114.197 & 255.872 & 6.160 & 9.160 & 1.989 & 8.805 & 10.793 & 17.965 & 7.775 \\
\hline & Maximum increase in EF for elec. & - & - & - & - & - & - & 9.160 & 1.832 & 7.831 & 9.663 & 16.991 & 1.930 \\
\hline
\end{tabular}




\section{Conclusion}

Parameter or scenario uncertainty was conducted to empirically investigate and evaluate key parameters and issues that contribute to high variations in EE and EC intensities of building materials in Malaysian construction industry. This study found that maximum increase in energy tariff and material price fluctuation was the key parameters and issues leading to higher variations in EE and EC intensity values. Other parameters such as maximum increase in primary energy factor, emission factor and excluding disaggregation constant have a slight impact upon EE and EC intensity variations. The high variations of EE and EC intensities in hybrid LCA model can be clearly seen between energy and non-energy intensive materials due to the high contribution of indirect energy in non-energy intensive materials in upstream boundary of materials production. Therefore, any decision relating to these materials should be considered carefully. Thus one strategy to reduce uncertainty and increase reliability of hybrid LCA data is by firstly calculating EE and EC intensities of materials and products, and then computing EE and EC of the entire building by using actual quantities of material, labor and equipment (process LCA). This in turn can reduce the high variations of $\mathrm{EE}$ and $\mathrm{EC}$ intensity values caused by high dependency on the aggregated industry sectors in the I-O tables (i.e. residential and non-residential sector used in Malaysian I-O tables).

\section{References}

[1] N.S. Mohd Safaai, Z.Z. Noor, H. Hashim, Z. Ujang, J. Talib, Projection of $\mathrm{CO}_{2}$ emissions in Malaysia, Environmental Progress \& Sustainable Energy, 30 (2011) 658-665.

[2] G.J. Treloar, A Comprehensive Embodied Energy Analysis Framework, in: Faculty of Science and Technology, Deakin University, Australia, 1998.

[3] R.H. Crawford, Using Input-Output Data in Life Cycle Inventory Analysis, in, Deakin University, Victoria, Australia, 2004.

[4] M. Lenzen, G. Treloar, Embodied energy in buildings: wood versus concrete-reply to Börjesson and Gustavsson, Energy Policy, 30 (2002) 249-255.

[5] M.K. Dixit, J.L. Fernández-Solís, S. Lavy, C.H. Culp, Identification of parameters for embodied energy measurement: A literature review, Energy and Buildings, 42 (2010) 1238-1247.

[6] M.K. Dixit, J.L. Fernández-Solís, S. Lavy, C.H. Culp, Need for an embodied energy measurement protocol for buildings: A review paper, Renewable and Sustainable Energy Reviews, 16 (2012) 3730-3743.

[7] G. Baird, A. Alcorn, P. Haslam, The Energy Embodied in Building Materials - Updated NZ Coefficients and Their Significance, in: IPENZ Transactions, Institution of Professional Engineers New Zealand, Wellington, N.Z, 1997, pp. 89-94.

[8] International Energy Agency, Malaysian energy balance 2005, in, International Energy Agency (IEA), France, 2005.

[9] Malaysian Energy Comission, Malaysian national energy balace (NEB) 2009 in, Ministry of Energy, Green Technology and Water, Malaysia, Putrajaya, Malaysia, 2009.

[10] A.A. Acquaye, A Stochastic Hybrid Embodied Energy and $\mathrm{CO}_{2}$ eq Intensity Analysis of Building and Construction Processes in Ireland, in: School of Civil and Building Services Engineering, Dublin Institute of Technology (DIT), Ireland, Dublin, 2010.

[11] Malaysian Department of Statistics, Input-Output Tables Malaysia 2005 in, Department of Statistics, Malaysia, Malaysia, 2010.

[12] W.M.S. Wan Omar, J.H. Doh, K. Panuwatwanich, D. Miller, Assessment of the embodied carbon in precast concrete wall panels using a hybrid life cycle assessment approach in Malaysia, Sustainable Cities and Society, 10 (2014) 101-111.

[13] L. Price, S.d.1.R. du Can, J. Sinton, E. Worrell, Z. Nan, J. Sathaye, M. Levine, Sectoral Trends in Global Energy Use and Greenhouse Gas Emissions, in, Environmental Energy Technologies Division, Lawrence Berkeley National Laboratory, 2006.

[14] Malaysian Energy Centre, Study on grid connected electricity baselines in Malaysia in, Malaysian Energy Centre, Malaysia, 2008. 